\title{
Study of the Sediments Metallic Contamination in Oum Er-Rbia Estuary
}

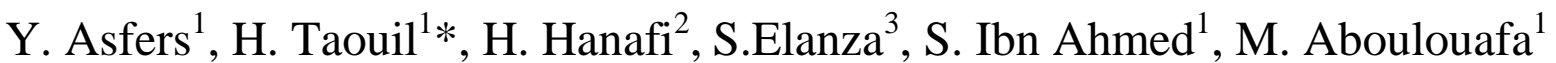 \\ ${ }^{1}$ Laboratoire de Synthèse Organique et Procédés d'Extraction, Université Ibn Tofail. Département de Chimie, \\ B.P. 133, 14000 Kenitra, Maroc \\ ${ }^{2}$ Laboratoire de Physico-Chimie des Matériaux et Environnement. Université Abdelmalek Essaâdi, Faculté des \\ Sciences, B.P. 2121, Tétouan, Maroc. \\ ${ }^{3}$ Laboratoire de Synthèse Organique et Procédés d'Extraction, Département de Chimie, Faculté des sciences, \\ Université Ibn Tofail, Kenitra, Maroc \\ *Corresponding author: Email: hamidsup@yahoo.fr
}

\begin{abstract}
Summary: This work fits in the framework of a program of study and monitoring of the Impact of natural and anthropogenic Factors on the quality of surface waters of the river Oum Er-Rabia (Morocco); it focuses on the analysis and evaluation of the metal contamination of the sediments of this stream using an index of contamination (IC) and the index of polymetallic contamination (ICP). The spatial and temporal variations of the sediment content in $\mathrm{Fe}, \mathrm{Mn}, \mathrm{Cd}, \mathrm{Zn}, \mathrm{Cu}, \mathrm{Pb}, \mathrm{Cr}$ and Co reveal the presence of an important metal contamination, dominated mostly by $\mathrm{Pb}, \mathrm{Cd}, \mathrm{Cr}, \mathrm{Zn}$ and Co however at the level of the mouth where the metal concentrations are very low. From this fact situation does not pose a concern for the ecosystem in the vicinity of the downstream of the estuary, this finding is related can be the size and the fraction of the mouthpiece sediments.
\end{abstract}

Keywords: Oum er-Rbia Estuary, metallic contamination, heavy metals.

\section{Introduction}

The metal contamination of the aquatic ecosystem to attract the attention of several researcher in Morocco (1-3). In particular, the study of heavy metals in sediments is a contribution to the determination, understanding and prediction of the metal pollution (4). This contribution is especially important that this compartment may as well, according to its nature and environmental conditions, play the role of tank in case of a massive contribution, or the role of pollution source if the conditions of release are favourable. On the one hand, very few studies have been conducted so far to assess the level of pollution by heavy metals during Moroccan water from studying their sediments. On the other hand, there is only one working Kaimoussi (5) to our knowledge of metal concentration data in sediments of Oum Er-Rabia estuary, a stream with a very important regional interest. The estuary of Oum Er Rabia is an environment conducive to sedimentation and is subject to a variety of sources of contamination, and this, for several decades. The sediments of the estuary constitute true indicators of the history of contamination of fresh water from the Oum Rabia. The physical, chemical and biological interactions that occur between fresh water and sea water can have influences on the transport of ETM in sediments. The accumulation of these elements in sediments can have serous environmental problems and especially aquatic organisms.

\section{1-Location of study sites}

\section{Material and methods}

For the realization of this work and taking into account of the various activities identified in the area, (domestic and agricultural wastewater. Industry and Fisheries), the spread sediments taking stations along the estuary were selected, are defined as follows (figure 1):

- S1: Station located before dam Sidi dawi $15 \mathrm{~km}$ from the mouth. Considered a reference station (SR) far from anthropogenic, domestic, industrial and agricultural inputs.

- $\quad$ S2: located on dam Sidi dawi, symbolized by dam station.

- S3: station receives the agricultural wastewater, named agricultural station

- S4: Station located on the river and opposite the wastewater from the industrial unit 'Unimer "Symbolized by industrial station.

- S5: station receives the wastewater from the main collector C1. (.S manifold)

- S6: station on Wadi located in the vicinity of the Collector C2. (.S manifold)

- S7: Station located at the mouth of the estuary. (S mouth) 


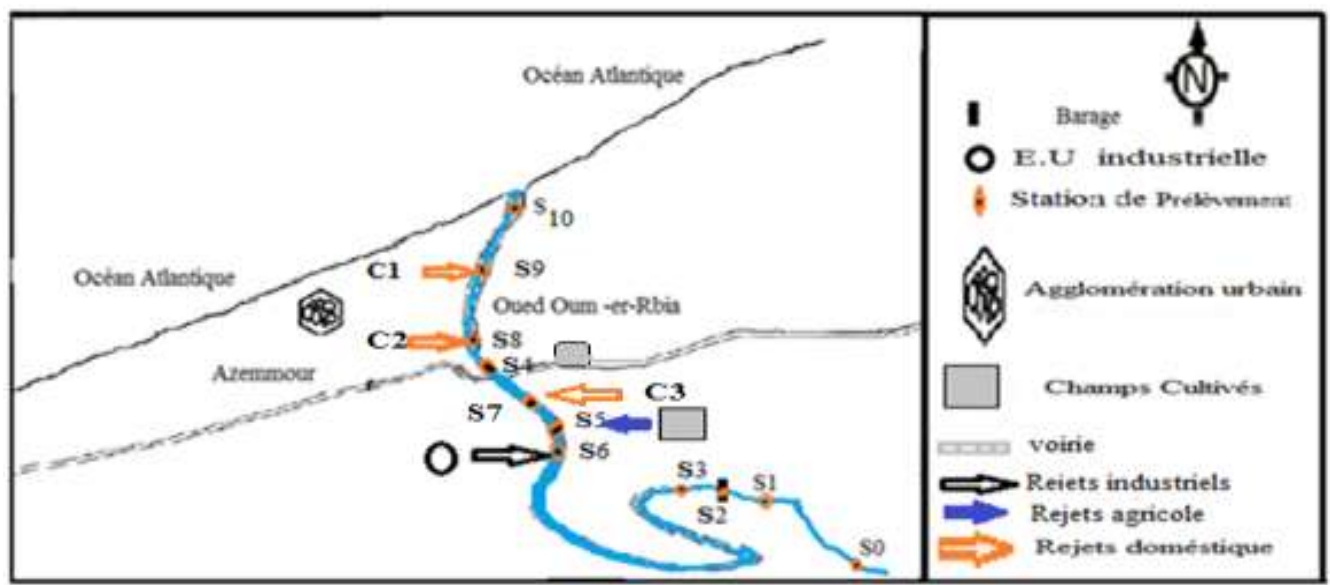

Figure. 1: Location of study sites

\section{Sampling Techniques}

Sampling of surface sediments of the estuary of Oum Rabia was directed by core manual with a $5 \mathrm{~m}$ length and $15 \mathrm{~mm}$ diameter core drill down into sediment to more compact level to $5 \mathrm{~cm}$ depth. The levy must meet the following conditions:

- The samples were taken in the middle zone (intertidal zone) between the high and low tide

- All samples of the same companion were carried out in the same day.

- Metallic Evaluation involved two sampling seriated during low water and winter.

\section{3- Processing of sediment}

\section{3-1. particle size processing}

The determination of metals is generally carried out either on the total sample either on a particle size fraction of the sediment. The first method has the merit to simplify the operations and especially not to introduce change in its metal content. However, the determinations made in these conditions may sometimes not be comparable.

To remedy this problem, the simplest method is to analyze a particle size fraction well defined and that is the same for all the samples of a given study.

For our case, we have therefore opted for the second method which enables:

- To avoid variations in composition due to particles size variations, while keeping the whole fractions of adsorbed sediment;

- To obtain the particle size the more homogeneous as possible to perform in good conditions of comparisons between the sediment from the different sampling stations.

The metals studied in the framework of our study have therefore been assayed in the dry sediment samples and crushed Below $50 \mu \mathrm{m}$ in diameter. However, many authors $(6,7,8)$ determine the metals in the fractions are much finer, such that the fraction less than $50 \mu \mathrm{m}$. In the station located on the mouth, the fine fraction less than $50 \mu \mathrm{m}$ represents a rate which does not exceed 15 to 20 per cent of total sediment because of the nature of sandy of this station. This requires a significant amount of the sample to crushed and sieved.

\section{3-2. Mineralogy Processing}

Sediments Intended for analyzes were collected using a non-metallic tool, the mineralization of sediment that consists in an attack acid to destroy the organic matter, has been carried out according to the wet track. In the laboratory, it has been carried out after drying and crushing of the sediment, in beakers in the presence of a mixture of nitric acid/hydrochloric acid pure $(7.5 \mathrm{ml} / 2.5 \mathrm{ml})$ and then heated on a plate to $70^{\circ} \mathrm{C}$ approximately two hours, while being covered by the watch glasses in order to condense the steam. Heating continues until total disappearance of nitrous vapours red and clear appearance of smoke. Then the samples are evaporated to dryness. The mineral deposit is taken up by successive rinses with distilled water and filtered and made up to a final volume of $100 \mathrm{ml}$.

\section{3-3. Determination of heavy metals}

Metal determination in the supernatant was carried out by atomic absorption spectrometry in flame and furnace for low concentrations. 


\section{Results and Discussion}

The results of analysis of heavy metals in sediments sampled are summarized in the following table

Table 1: Average grades and levels of unit $\mathrm{g} / \mathrm{g}$ to the Iron exception in $\mathrm{mg} / \mathrm{g}$ of some metals in surface sediments of the Oum Er-Rabia during low water and winter

\begin{tabular}{|c|c|c|c|c|c|c|c|c|c|}
\hline & saison & $\mathbf{F e}$ & $\mathbf{C u}$ & $\mathbf{P b}$ & Cd & $\mathrm{Cr}$ & Co & $\mathbf{Z n}$ & Mn \\
\hline \multirow[t]{3}{*}{ S1-reference } & January & 6.5 & 10.77 & 0.54 & 0.89 & 12.25 & 1.11 & 68.21 & 112.47 \\
\hline & June & 5.45 & 18.22 & 1.18 & 0.12 & 9.87 & 0.97 & 24.87 & 147.55 \\
\hline & average & 5.97 & 14.49 & 0.86 & 0.50 & 11.06 & 1.04 & 46.54 & 130.01 \\
\hline \multirow[t]{3}{*}{ S2-dam } & January & 7.68 & 17.27 & 7.68 & 0.77 & 7.68 & 1.91 & 216.82 & 456.67 \\
\hline & June & 8.12 & 19.01 & 7.98 & 0.97 & 8.41 & 1.85 & 311.12 & 345.14 \\
\hline & average & 7.9 & 18.14 & 7.83 & 0.87 & 8.04 & 1.88 & 263.37 & 400.90 \\
\hline \multirow[t]{3}{*}{ S4 - Agricol } & January & 13.87 & 16.64 & 24.96 & 2.77 & 36.06 & 5.54 & 72.11 & 390.61 \\
\hline & June & 14.25 & 20.47 & 44.54 & 3.44 & 47.24 & 5.87 & 81.25 & 410.21 \\
\hline & average & 14.06 & 18.55 & 34.75 & 3.10 & 41.65 & 5.70 & 76.68 & 400.51 \\
\hline \multirow[t]{3}{*}{ S6- industrial } & January & 17.25 & 56.06 & 21.56 & 0.86 & 62.52 & 4.31 & 120.74 & 230.70 \\
\hline & June & 12.35 & 61.23 & 31.47 & 1.25 & 77.54 & 2.14 & 119.02 & 247.14 \\
\hline & average & 14.8 & 58.64 & 26.51 & 1.05 & 70.03 & 3.22 & 119.88 & 238.92 \\
\hline \multirow[t]{3}{*}{ S8- collector 1} & January & 23.23 & 38.02 & 6.34 & 2.11 & 48.58 & 2.11 & 124.62 & 95.05 \\
\hline & June & 33.25 & 41.25 & 7.89 & 4.36 & 52.11 & 5.66 & 132.02 & 100.21 \\
\hline & average & 28.24 & 39.63 & 7.11 & 3.23 & 50.34 & 3.88 & 128.32 & 97.63 \\
\hline \multirow[t]{3}{*}{ S9-collector 2} & January & 25.36 & 40.58 & 8.25 & 2.01 & 44.51 & 4.55 & 108.5 & 122.54 \\
\hline & June & 24.69 & 32.54 & 9.54 & 2.54 & 40.21 & 5.55 & 145.36 & 154.12 \\
\hline & average & 25.02 & 36.56 & 8.89 & 2.27 & 27.36 & 5.07 & 126.93 & 138.33 \\
\hline \multirow[t]{3}{*}{ S10- mouth } & January & 5.36 & 12.55 & 1.79 & 1.79 & 19.72 & 1.79 & 46.60 & 102.53 \\
\hline & June & 7.03 & 12.03 & 1.90 & 1.87 & 22.11 & 1.91 & 44.51 & 120.15 \\
\hline & average & 6.19 & 12.29 & 1.84 & 1.83 & 20.91 & 1.85 & 45.55 & 111.34 \\
\hline
\end{tabular}

\section{2-Distribution of heavy metals in the sediments of the watershed Oum Er-Rbia.}

To obtain the best comparison conditions in an environmental study, it is necessary that these reference samples are many, have equivalent particles size and compositions and identical geological origins. Several possibilities have been discussed to establish the background noise. It is thus possible to relate to the table.1. The average composition of the shale in the measure can be considered as the present fossil shale clay sediments. This approach has been advocated by (6). These reference values are reported in the table .2. Aquatic Sediments fossil environment well defined: the sediments of the Lake of meteoric origin in Germany by example (7). Recent deposits in non-contaminated areas. It will however be necessary to distinguish early diagnosis will modify such contents $\mathrm{Mn}$ and Fe co-precipitation with carbonates. Short dated sediment cores that provide a historical record of events that have occurred in the watershed of a river of a lake or a particular estuary. These cores have a double advantage to the extent that, besides the possibility they offer to reach a reference level, they inform on changes in contributions over a certain period of time.

Table.1: Natural Makers TME expressed in sediment (mg / g dry weight)

\begin{tabular}{|c|c|c|c|c|c|c|c|}
\hline \multirow[t]{2}{*}{ Unpolluted sediment } & 13200 & $0 \quad 44,3$ & 16,6 & - & - & 0,1 & Nicolaidou et Nott (1998) (8) \\
\hline & - & 50 & 20 & - & 20 & 0,1 & O'reilly Wiese et al. (1995) (9) \\
\hline Unpolluted material & - & $<90$ & $<25$ & - & $<40$ & - & \\
\hline Moderately polluted & - & $90-200$ & $25-50$ & - & $40-60$ & - & Hamdy et Post (1985) (10) \\
\hline Very polluted & - & $>200$ & $>50$ & - & $>60$ & $>6$ & \\
\hline Fraction $<80 \mu \mathrm{m}$ & - & 75 & 25 & - & 50 & - & Robe (1981) (11) \\
\hline Fraction $<125 \mu \mathrm{m}$ & 47000 & 120 & 15 & - & 65 & 4 & \\
\hline Lake sediment & 43400 & 118 & 45 & - & 34 & 0,4 & Forstner (1977) (7) \\
\hline Rhin sediment & 32300 & 115 & 51 & & 0,3 & & Forstner et Mûller (1973) (12) \\
\hline
\end{tabular}

Table.2: level of reference concentrations of metals in the sediments purposes of different origins ( $\mu \mathrm{g} / \mathrm{g}$ of dry weight; RNO, 1998) (9).

\begin{tabular}{|c|c|c|c|c|c|}
\hline Regions & $\mathrm{Zn}$ & $\mathrm{Cu}$ & $\mathrm{Pb}$ & $\mathrm{Cd}$ & Sources \\
\hline Humber & 24 & 17 & 22 & - & Middleton et Grahn(1990) \\
\hline Wadden Sea & 103 & 22 & 37 & - & Kramer et al. (1984) \\
\hline Rade de Venise & 49 & 15 & 23 & 0,2 & Donazolo et al. (1984) \\
\hline Ligure sea & $60-85$ & $20-30$ & - & - & Cauwet et Monaco(1982) \\
\hline \multicolumn{6}{|c|}{$\begin{array}{l}\text { Mediterranean background } \\
\text { noise }\end{array}$} \\
\hline Côte Française & 90 & 30 & 30 & 0,15 & R.N.O. (1998) \\
\hline Loukkos estuary & 115,41 & 16,85 & 69,26 & 1,10 & EL MORHIT (2009) (14) \\
\hline Oum Er Rbia estu & $\operatorname{ary} 46.54$ & 14.49 & 0.86 & 0.5 & présent travail \\
\hline
\end{tabular}


From Table.1 which includes the concentrations considered as natural of different types of sediment, the work of the National Network for Observation of Marine Environmental Quality (13) adopted that concentrations do not exceed $0.15 \mathrm{mg} / \mathrm{g} \mathrm{Cd}, 30 \mathrm{mg} / \mathrm{g}$ of Pb, $30 \mathrm{~g} / \mathrm{g}$ of Cu and $90 \mathrm{~g} / \mathrm{g} \mathrm{Zn} \mathrm{do} \mathrm{not} \mathrm{mean} \mathrm{a}$ significant contamination of surface fine sediment. The determination of heavy metals in the sediments is a quantitative aspect. In effect, the assessment of their degree of pollution should be the share of what actually originates of releases, but also of the availability of these metals with other components of the aquatic environment (15). The characterization of the content in metallic elements of the sediments is essential. Given that the major part of the various pollutants commonly observed in aquatic environments is always ultimately more at least associated with sediment. It is therefore appropriate to constantly monitor the evolution of the levels of metals of our aquatic environment in order to be able to pull the alarm and to take the necessary measures as soon as these levels exceed the allowable limits. The results of the determinations of the levels of metals in the sediments studies are presented in the following manner:

- For each station of study we have calculated the average concentrations for each metal and we have brought it in a table.

- We have plotted for each metal in the same graph. The longitudinal profile of the average of the levels recorded during the two companions: winter and low water.

\section{- Iron}

Levels averages vary between 5.97 and $28.24 \mathrm{mg} / \mathrm{g}$. The most important values are those obtained in the Stations S4, S6, S8, and S9. Remember that these stations receive directly the domestic wastewater for industrial and agricultural products; these last are rich in organic matter which plays the role of a support for the precipitation of $\mathrm{Fe}$ in the sediments (5). At the level of the station of mouth we note a sharp fall in the concentration of Fe, this can be binding to:

- The sediments of the mouth are mostly sandy and contain low organic matter contents.

- Winnowing exercised by the overflow of sediment due to the strong currents at low tide this impoverishes the substrate fine particles that can trap the metals.

The comparison of different metal contents shows that the content of all stations differs significantly with the natural metal concentrations. Indeed the higher levels do not exceed $47 \mathrm{mg} / \mathrm{g}$ (faction $<125 \mathrm{mg} / \mathrm{g}$ ) and $43.4 \mathrm{mg}$ / g (lake sediment) that represent the levels considered natural levels (respectively dress forstner 1981 and 1977) (3-7) this reflects that there is no contamination.

\section{- Copper}

The average copper concentration varies between $12.29 \mathrm{~g} / \mathrm{g}$ and $58.64 \mathrm{~g} / \mathrm{g}$. comparing different levels between them and the content of the reference station (Table 1) shows that the content of the latter has significant differences with the different levels recorded at other stations. Indeed all stations have less low levels do not exceed 51ug / g representing natural levels in coastal sediments (12). Except station S6 has a higher content exceeds the value $51 \mathrm{ug} / \mathrm{g}$ reflecting a contamination survey site. The longitudinal profile shows that the highest average levels were observed at stations S6, S8, and S9. This is related to massive inflows of industrial and urban waste of the city Azemmour. Comparing our average contents of $\mathrm{Cu}$ in different station to those found by other authors (14-27) in different basins, shows that our site is quite contaminated.

\section{- Lead}

The mean levels of lead oscillate between 0.86 and $34.75 \mathrm{ug} / \mathrm{g}$ (fig). The high content is observed at the level of the station S4 which is located on the oued Oum er-Rabia, just in the vicinity of the cultivated fields. Therefore the source of pollution by this element could be anthropogenic. We also note a quite important content at the station S6 $(26.51 \mathrm{ug} / \mathrm{g})$. The station S6 is located in the vicinity of an industrial unit; this result could be explained by the discharge of wastewater from this unit. Nevertheless, the station S1 considered in this study a station of references, presents a very low content in $\mathrm{Pb}$ element, this station is located far away from any source of litho-genetic pollution, and therefore the enrichment in lead at the level of the station could be due to inputs litho-gene. In effect all the stations exhibit of low levels do not exceed 30ug/g which represents concentrations regarded as natural in the coastal sediments (13). Except station S4 presents content largely superior to $30 \mathrm{ug} / \mathrm{g}$ which reflects a contamination of the environment.

\section{- Cadmium}

Surface sediments of our study site have average levels of cadmium ranged from a low of $0.50 \mathrm{ug} / \mathrm{g}$ recorded at the station S1 (base station) and a maximum value of 3.23ug / g observed in the station S8. The longitudinal profile shows that relatively high contents are obtained in S4 stations, S8 and S9. This is related to the importance of domestic and agricultural discharges. And leaching of fertilized soil can also be a source of cadmium intake. Indeed analysis of metals on phosphate fertilizer and potash has revealed grades up to $6.3 \mathrm{~g} /$ 
$\mathrm{kg}$ of Cadmium (16). As a result, the burden of this element can have an agricultural origin. It is further the different contents obtained at the study sites exceed the natural content $(0.15 \mu \mathrm{g} / \mathrm{g}$. RNO 1998) (13).that reflects a metal contamination of the survey site.

\section{- Chromium}

In our study the average grades of chrome fluctuate between 8.04 and $70.03 \mu \mathrm{g} / \mathrm{g}$ compared these two extremes one can say that the change of contents in different stations is significant. The high concentration recorded at the station S6, which receives a mass contribution of industrial wastewater rich in organic matter. However, the existence at that station of a black layer lining the surfaces in this area is related to the enrichment of sediment organic matter, therefore the latter are able to trap and concentrate the heavy metals. Comparing the different levels between them and the content of the reference station $([\mathrm{Cr}]=100 \mu \mathrm{g} / \mathrm{g}$ suspension of the estuary unpolluted BUST 1981) (17) shows that the level of the latter has significantly different with different contents obtained at stations which indicates that there is no contamination. The high values found at the stations S4, S8, and S9 may be related to urban and agricultural anthropogenic inputs.

\section{- Cobalt}

Cobalt levels fluctuate between an average value of $1.04 \mu \mathrm{g} / \mathrm{g}$ registered at the level of the reference station (S1) and a maximum value of $5.70 \mu \mathrm{g} / \mathrm{g}$ at the level of the station S4, note that this last station directly receives the wastewater in the cultivated field. Then the enrichment of $\mathrm{Co}$ in this station is linked to the leaching of agricultural land. Comparing the different levels between them and the content of the reference station $25 \mathrm{ug} / \mathrm{g}$ soil (18) finds that the content of the latter presents significant differences with the different levels achieved at the level of the stations. This reflects that there is no contamination of the environment.

\section{- Zinc}

The variation in mean levels between the stations explored is widely significant. The levels are between $45.55 \mu \mathrm{g} / \mathrm{g}$ and $311.12 \mu \mathrm{g} / \mathrm{g}$. However sediment samples collected at the level of the station located on dam are characterized by high concentrations of $\mathrm{Zn}$, which shows that the power of the accumulation of this metal in the sediments of this course of water is more important. In addition, we note that the station swallows less contaminated presents a low content (station of the mouth).This low load in $\mathrm{Zn}$ may be related to the dynamic tidal effects of the estuary Oum er-Rabia. However the return of marine waters highly mineralized causes a remobilization and a leaching of metals from sediments and their transformation into ionic form, the most toxic form (19). In addition to that, the hydrodynamic effect, the texture and the size of the particles of the mouth sedimentary are of coarse sand and are suspected to be an essential factor attach little the micro pollutants. By comparing the different levels between them and the content of the reference station (Table1), we find that the higher content of the stations exceeds this obtained at the level of the reference station. (90$200 \mu \mathrm{g} / \mathrm{l})$ that is represented by the coastal sediments (10), which reflects that there is a contamination of the environment by this element.

\section{- Manganese}

For all campaigns of levy that we have carried out, the longitudinal profile average levels of manganese presents a pace seems to be that of the $\mathrm{Zn}$. For Oum er-Rabia oued, the levels of manganese are gradually decreasing of the upstream of the agricultural station to downstream of the oued, station of the mouth. The high mean levels recorded at the level of the sediments of the station S4 can be due either:

* To the fact that the anthropogenic activities are more important at the level of the station S4.

* To the fact that the natural levels in this metal are stronger at the level of the station S4 level and at the level of the other stations. However, the study of the natural levels of manganese in the sediments of the stations surveyed showed that the second explanation is more likely. It reflects the fact that high levels of manganese, recorded in sediment station S4, are mainly due to litho-genetic contributions. On the other hand, it is noteworthy that for all sampling campaigns, lower concentrations of this element is recorded in sediments of the S10 mouthpiece station, station where sediments are mostly sandy and contain low organic matter. Manganese is found in sediments analyzed to smaller levels; its average concentration varies between 100.21 and 400.51 $\mathrm{mg} / \mathrm{g}$. comparing the different levels between them and the content of the reference station, we see that the highest content of stations does not exceed that obtained at the reference station. (960 mcg / g old sediments of the Rhine) (17), indicating that there is no contamination of the environment by this element 

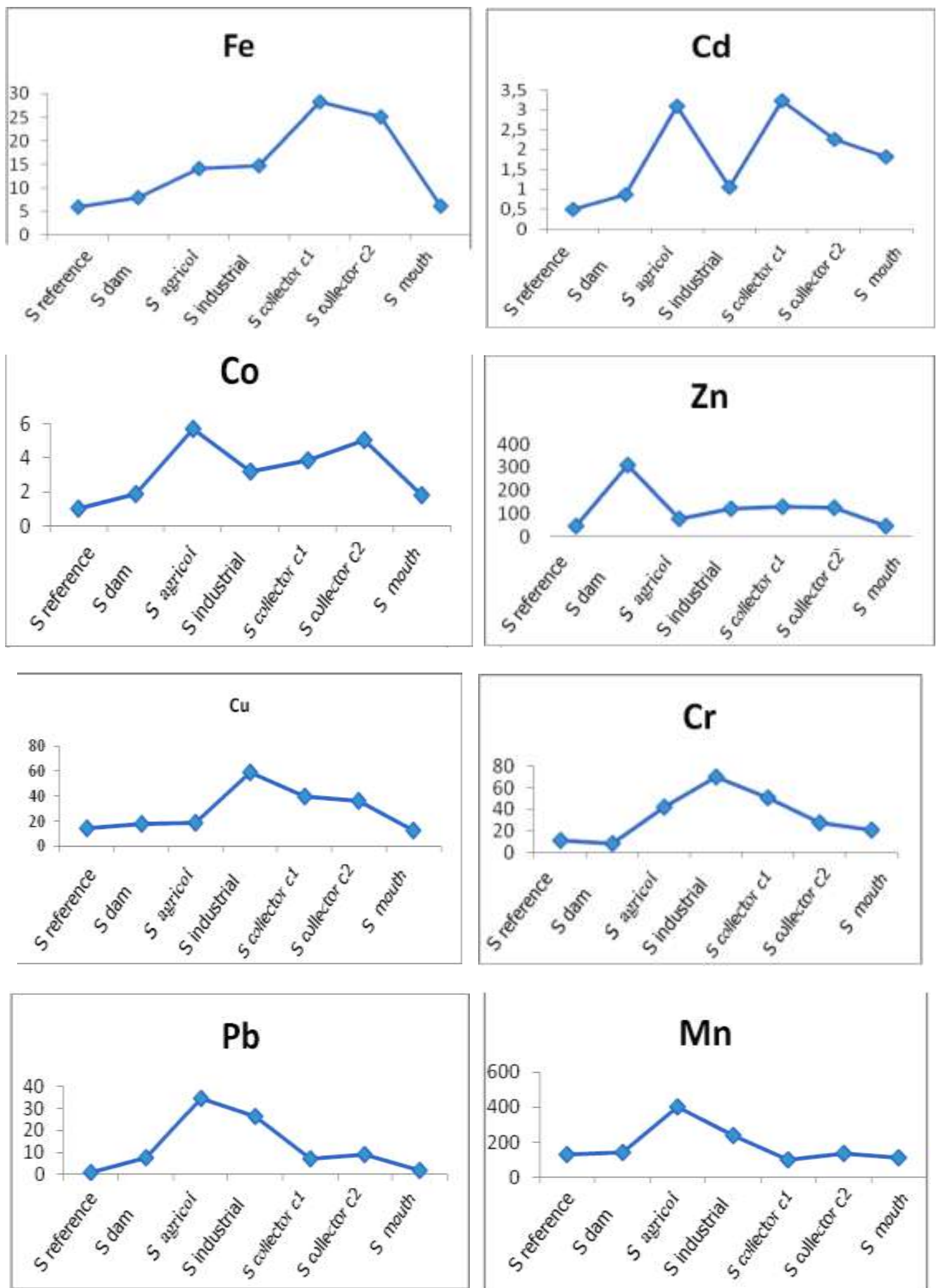

Figure .2: longitudinal profiles mean levels of heavy metals in the sediments of the estuary of the watershed of the oued Oum Er Rabia

\section{Evaluation of the degree of metal contamination of sediments}

The determination of heavy metals in sediments is an assessment instrument level metal pollution of the aquatic environment. However, the raw results are relatively comparable between them because the sediments can trap and store an even flow pollutant in a more or less important depending on their chemical composition (20). As well the index of contamination depends on the natural data used. For the total content of the metal in the sediment, it can provide these data the average concentrations of metal of texture and sediment 
mineralogically equivalents, announced in the literatures or measured by the authors in a region primitive known (21-22), the techniques of standardization by the concentration of iron and the correction of the fraction $<63 \mu \mathrm{m}$ are adopted to differentiate between the anthropogenic input and natural (23-25). During the course of our study, we have adopted the index of contamination (IC), which takes account of the levels of Reference and this to attempt to locate the current state of the metal pollution of the estuary Oum Er- Rabia. The interpretation and especially the evaluation of the result of the index of contamination of the sediment are dependent on the knowledge of the levels of Reference. However, these are difficult to establish in a definitive manner because of their great heterogeneity related primarily to physico-chemical parameters, geochemical and lithological.

\section{3-2. Evaluation of the degree of contamination}

To compare the stations in relation to each other, we calculated an index of contamination (IC) which is defined by a given element, as the report of the measured content on the natural content measured at the level of the reference station according to the following formula (20).

$$
\mathrm{IC}=\frac{\text { metal content }}{\text { content of reference }}
$$

- If IC close to 2; the sites considered as little or not polluted by the sediments.

- If IC is less than 2; it is in this time an analytical error of a further dilution.

- If IC is higher than 2; the degree of pollution is large.

Assuming that all the micro even have a polluting power, we can calculate the average contamination index (ICM) which represents the arithmetic mean of the station concerned.

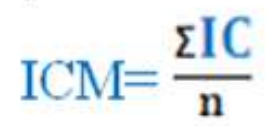

\section{With n: number of metals considered}

This approach enables full characterization of the various resorts, especially for toxic metals that sometimes it is difficult to value the simple observation of particular values. CI for each element, each station and the ICM at the seven sampling stations are shown in Table 3 and Figures 3 and 4. The value of the index of contamination is that it allows comparing the degree of pollution of different locations relative to a referential average (reference station); due to its location away from any human disturbance and its low contents of metals. It is considered as reference station (SR) knowing that it does not receive industrial discharges. The results obtained show evidence of contamination more or less important depending on the station and metals. The stations have IC> 2; show the contribution of human activity (26). The IC $<2$ show the natural supply watershed rather than Anthropogenic contributions (Table 3).

Table 3: Contamination Index (IC) and indices Contamination Medium (ICM) calculated relative to the reference station in sediments of the estuary of Oum Er Rabia

\begin{tabular}{|l|l|l|l|l|l|l|l|l|c|}
\hline IC & Fe & Cu & Pb & Cd & Cr & Co & Zn & Mn & ICM \\
\hline S reference & 1 & 1 & 1 & 1 & 1 & 1 & 1 & 1 & \\
S dam & 1.32 & 1.25 & 9.10 & 1.74 & 0.72 & 1.80 & 6.68 & 2.65 & 3.15 \\
S Agricola & 2.35 & 1.28 & 40. & 6.2 & 3.76 & 5.48 & 1.64 & 3.08 & 8.02 \\
S industrial & 2.47 & 4.04 & 30.82 & 2.1 & 6.33 & 3.09 & 2.57 & 1.83 & 6.65 \\
S collector C1 & 4.73 & 2.73 & 8.26 & 6.46 & 4.55 & 3.73 & 2.75 & 0.77 & 4.24 \\
S collector C2 & 4.19 & 2.52 & 10.33 & 4.54 & 2.47 & 4.87 & 2.72 & 1.06 & 4.08 \\
S mouth & 1.03 & 0.84 & 2.13 & 3.66 & 1.89 & 1.77 & 0.97 & 0.85 & 1.64 \\
\hline
\end{tabular}

The analysis of Table 3 shows that the contamination indices related to Chrome, cobalt, copper, cadmium and iron 1a station dam sediments are lower than 2. This allows us to say that the estuary basin slope of the Oum Er-rabia can be considered an unpolluted environment with these five metals at this station. However, it seems that the sector situated at the dam station knows slightly polluted by manganese. Indeed, the contamination factor by the manganese sediment that station is of the order of 2.65. Moreover, it is noteworthy that the factors of contamination by lead and zinc sediment (Table 3); calculated for this sampling station, show that the estuary watershed of the Oum Er-Rabia could be regarded as a medium polluted by lead and zinc. However, this contamination is relatively larger by the lead which its source of contamination is of the order of 9.10 , by which its zinc contamination factor is of the order of 6.68 . However, the downstream sector of the estuary (mouth station) does not know the metal pollution is: Iron, Copper, Chromium, Cobalt, Zinc and Manganese, contamination factors these metals sediment are lower than 2 . by hand, it should be noted that contamination factors by lead and cadmium sediment (table 3), calculated for this sampling station, show that the watershed of the Oum Er-rabia could be considered a medium polluted by the two metallic elements. As for the levels of stations: S Agricultural, industrial S, SC1, SC2 collector and collector. The results obtained on the 
figure (3) show a much higher contamination and localized by iron metals, $\mathrm{Pb}, \mathrm{Co}, \mathrm{Cd}$, their $\mathrm{IC}$ experiencing a dramatic increase with values up to 40.40 and 30.82 for $\mathrm{Pb}$ successively in the agricultural station and industrial. Both situations reflect the state of the point toxic load of certain industrial and agricultural units carried by the waters of the estuary, is added to this side intakes and also some metal elements carried by runoff, mainly phytosanitary treatment period (pesticides) (14).

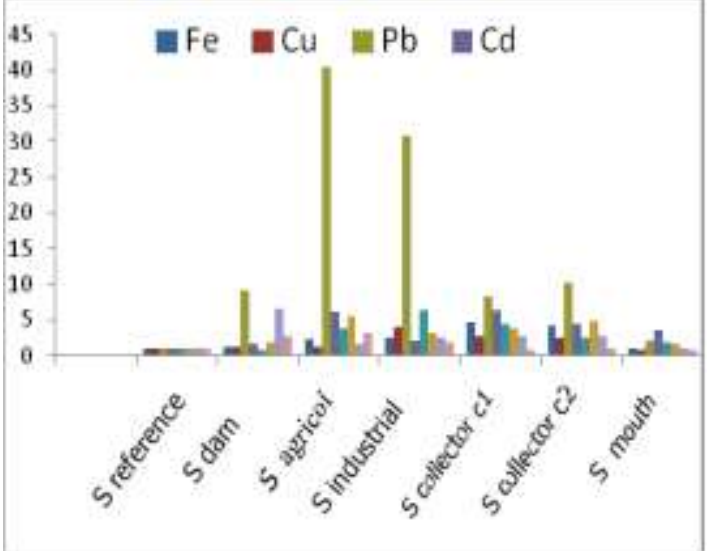

Figure 3: Spatial variation of sediment IC

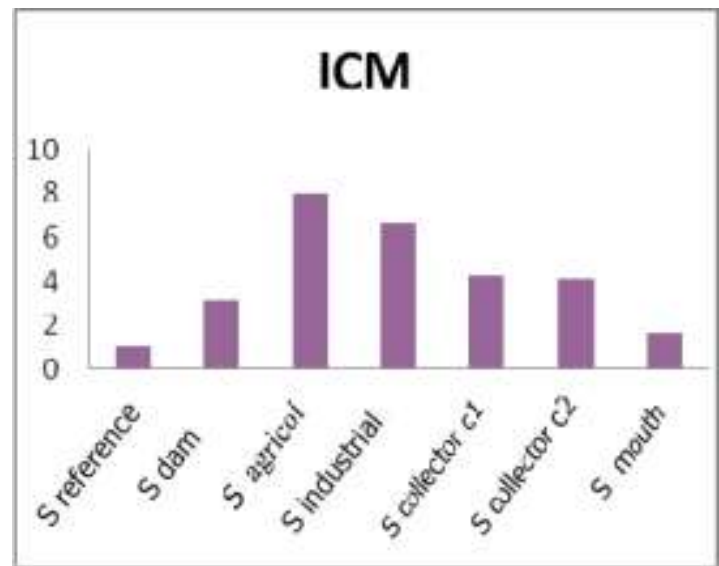

Figure 4: Spatial variation of sediment ICM

\section{Conclusion}

The use of indices ( $\mathrm{Ij}$ ) pollution and contamination factors (Fi) is a very important tool for assessing the degree of sediment contamination of aquatic environments by heavy metals. In fact, the classification of stations in order of increasing global pollution, heavy metal, established above, and characterization in this part of the pollution of the estuary of Oum Er-Rbia by lead have could not be demonstrated by analyzing the longitudinal profiles of the mean levels of the studied metals, or by observation of specific values.

\section{References}

[1]. H. Taouil1 et al., 2014 -Evaluation of métal pollution: Aluminium, Zinc, Iron and Copper of Tiykomiyne well water (East Morocco). J. Mater. Environ. Sci. 5 (1) 177-182

[2]. H. Taouil1, S. Ibn Ahmed1, A. El Assyry, N. Hajjaji, A. Srhiri , 2013 - Water quality evaluation of the river Tislit-Talsint (East Morocco). J. Mater. Environ. Sci. 4 (4) 502-509

[3]. H. Taouil1, A. El Assyry, S. Ibn Ahmed, 2014- Metallic pollution of ground water in Tyikomiyne town (Eastern Morocco). Mor. J. Chem. $2 \mathrm{~N}^{\circ} 3,194-198$

[4]. Hamid Taouil et al.,2011- Contribution a l'évaluation de la pollution métallique des sédiments de l'oued tislit-talsint , bassin versant de guir ( Maroc oriental). ScienceLib Editions Mersenne : Volume $3, \mathrm{~N}^{\circ} 111109$

[5]. Aziz KAIMOUSSI, A. CHAFIK A. MOUZDAHIR et S. BAKKAS. Les métaux lourds dans les sédiments superficiels de la cote littorale de la région d'El Jadida et de l'estuaire d'Oum R'bia (MAROC). bull. iinst. Natn. Scien. tech. Mer de salammbo, vol. 27, 2000

[6]. TUREKIAN K.K. \& K.H. WEDPOHL, 1961. - Distribution of the elements in some major units of the earth's crust. Bull. Geol. Soc. Am., 72: 175-192.

[7]. FORSTNER U., 1977. - Metal concentration in recent lacustrine sediments. Arch. Hydrobiol., 80 : $172-191$.

[8]. NICOLAIDOU A. \& JA. NOTT, 1998. - Metal in sediment, Seagrass and Gasteropods near a Nickel smelter in Greece: possible interactions. Mar. Pollut. Bull., 36 (5): 360-365.

[9]. O'REILLY WIESE S.B., BUBB J.M. \& J.N. LESTER, 1995. - The significance of sediments metal concentration in tow eroding. Essex salt marshes. Mar. Pollut. Bull., 30 (3): 190-199.

[10]. HAMDY Y. \& L. POST, 1985. - Distribution of mercury, trace organics and other heavy metals in Detroit River sediment. J. Creat. Lakes Res., 11(3) : 353-365.

[11]. ROBE D., 1981. - Pollution métalliques du milieu naturel. Guide méthodologique de leur étude à partir des sédiments; rapport bibliographique. L.C.P.C, rapport de recherche LPC n ${ }^{\circ} 104$.

[12]. FORSTNER U. \& G. MÛLLER, 1973. - Heavy metal accumulation in river sediments, a response to environment pollution. Geofrum, 14: 53-62.

[13]. RNO., 1998. - Programmes actuels. Les contaminants chimiques dans les sédiments du littoral méditerranéen. Surveillance du Milieu Marin. Travaux du Réseau National d'Observation de la Qualité du Milieu Marin. Edition 1998. Ifremer et ministre de l'aménagement du territoire et de l'environnement, $12 \mathrm{p}$.

[14]. EL MORHIT M., FEKHAOUI M., ELIE P., GIRARD P., YAHYAOUI A., EL ABIDI A. \& JBILOU M. 2009. - Heavy metals in sediment, water and the European glass eel, Anguilla anguilla (Osteichthyes: Anguillidae) from Loukkos river estuary (morocco, eastern Atlantic). Cybium (sous presse).

[15]. ARNOUX A., NIENCHENSKI L.P. \& J. TASSOSSIAN, 1981. - Comparaison de quelques méthodes d'attaques des sédiments marins pour l'analyse des métaux lourds. J. français hydrol., 34 : 29-48.

[16]. Raven KP, leoppert RH. 1997. Heavy metals in the envirenement trace element composition of fertilizers and soil amendment.J.Enviro. Qual. 26: 551

[17]. BOUST D. (1981), Métaux traces dans l'estuaire de la Seine et ses abords. Thèse 3ème Cycle, Université de Caen

[18]. Conseil fédéral suisse, ordonnance sur les polluants du sol (Osol), 9 juin 1986. 
[19]. Alloway B. J. (1990). - Heavy metal in soils. Senior lecteurer in environmental science, Queen mary and west field college, university of London.

[20]. B.R.G.M/S.G.A.L. 1982. - Inventaire de degré de pollution des sédiments des cours d'eau. Bureau de recherche géologique et minière, services géologique régional d'Alsace

[21]. D.H. \& R.T.T. RANTALA, 1992. - Manual for the Geochemical Analyses of marine sediments and suspended particulate matter. Earth-Sci. Rev., $32: 235-283$.

[22]. GIBBS R.J., 1993. - Metals of the bottom muds in Townsville harbour, Australia. Environ. Pollut. , 81 (3): $297-300$.

[23]. RULE J.H., 1986. - Assessment of trace element geochemistry of Hampton roads harbour and mower Chesapeake Bay area sediments. Environ. Geol. Water Sci., 8: 209-219.

[24]. ERGIN M., SAYDAM C., BASTÜRK Ö., ERDEM E. \& R. YÖRÜK, 1991. - Heavy metal concentrations in surface sediments from the two coastal inlets (Golden horn estuary and Izmet bay) of the north-eastern sea of Marmara. Chem. Geol., 91: 269-285.

[25]. LEE C.L., FANG M.D. \& M.T. HSIEH, 1998. - Characterization and distribution of metals in surficial sediments in south-western. Taiwan. Mar. pollut. Bull. , 36 (6): 464-471.

[26]. ANGELIDIS M.O. \& M. ALOUPI, 1995. - Metals in sediments of Rhodes Harbour, Greece. Mar. Pollt. Bull., 31(4-12) : 273-276.

[27]. Abdelaziz ABDALLAOUI.- Contribution à l'étude du phosphore et des métaux

[28]. Lourds contenus dans les sédiments et de leur influence sur les phénomènes d'eutrophisation et de la pollution. Cas du bassin versant de l'oued Beht et de la retenue de barrage El Kansera., these doctorat ès-Sciences Physiques, 1998.UNIVERSITE MOULAY ISMAIL Faculté des Sciences de Meknès 